\title{
EVALUATION OF THE IMPACT OF SOME DISINFECTANTS USED IN POULTRY FARMS
}

\author{
EYAD ALNAJJAR ${ }^{1}$ and MOHAMMAD ALI ALEMADI ${ }^{2}$ \\ ${ }^{1}$ PHD. Poultry Diseases, Hama University \\ ${ }^{2}$ Professor in Poultry Diseases, Hama University
}

Received: 29 December 2016; Accepted: 5 January 2017

\begin{abstract}
The study was aimed to evaluation the efficiency of biosecurity procedures in broiler flocks in the middle region of Syria and design a system for biosecurity procedures in farms broiler chicken for prevention of the emergency diseases. The study was conducted on 7 broiler chicken farms with similar productivity, management and technical parameters as number of flocks, structure design of the houses and other services within a farm, in addition to the quality of technical supervision on theses farms.It was applied and carried out all biosecurity procedures related to the process of washing and disinfection of houses and used materials in the stage between two rearing flocks using different disinfectants which are available in the international and local Syrian marketing with varying concentration according recommendation of manufacturing and recommended parameters in the scientific literature and international scientific organizations and societies.The results of biosecurity procedures were evaluated in the as mentioned in the study using specific bacterial examinations and tests are linked with the bacteriology examination of the samples taken from air, floors, walls, and materials which would be used in the coming flock after complete diminish of the application of all recommended biosecurity procedures. Strategies had been suggested according to the bacterial examination to avoid bacterial epidemic and endemic diseases occurrences in the study farms.
\end{abstract}

Key words: (Biosecurity- Disinfection- Bacterial examination)

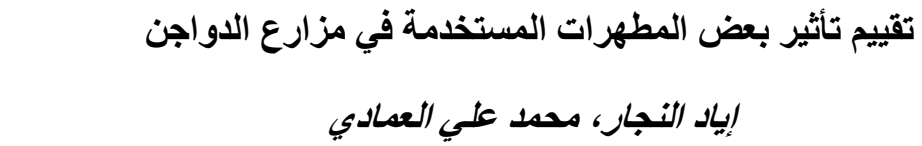

E-mail: eyadvet@hotmail.com Assiut University web-site: $\underline{\text { www.aun.edu.eg }}$

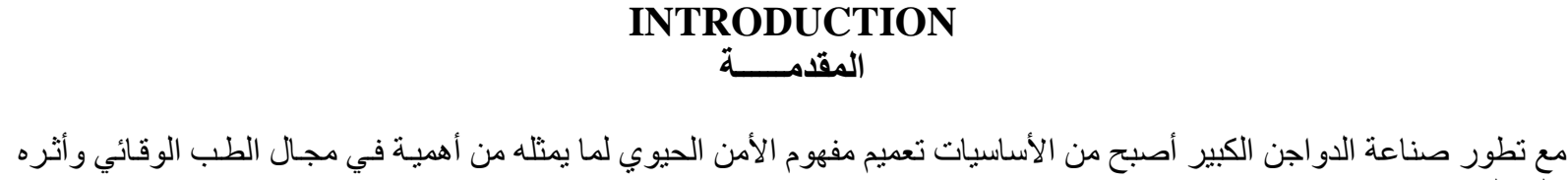
على الجانب الاقتصادي (Natural Recource, 1999).

يعد مفهوم الأمن الحيوي حديث النشأة نسبياً ومعناه واسع جداً ومن الصعوبة تقديم تعريف شامل له أو تحديده بدقة إلا أن هذا المصطلح

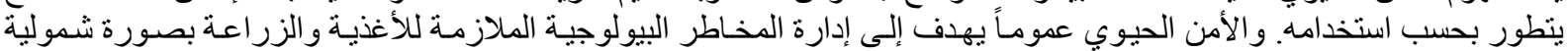

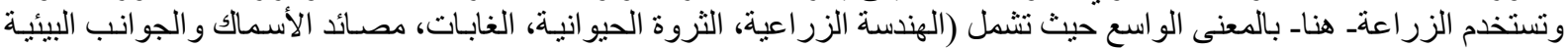
ذات الصلة).

ويعتبر الأمن الحيوي نهجاً استراتيجياً ومتكاملاً يشمل أطر السياسات والأطر التنظيمية لتحليل المخاطر و إدارتها في قطاعات سـلامة

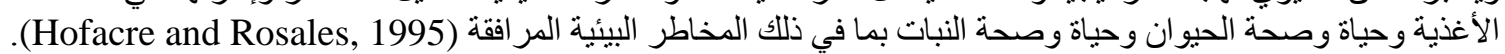

$$
\text { إن الحاجة لإجر اءات الأمن الحيوي كبيرة وهامة جداً حيث تتجلى أهميتها من خلال: }
$$

Corresponding author: Dr. EYAD ALNAJJAR

E-mail address:eyadvet@hotmail.com

Present address: PHD. Poultry Diseases, Hama University 
حماية نظم الانتاج الحيواني ومن يعتمد على هذه النظم حيث يمكن أن يفقد المنتجون أملاكهم وأرزاقهم بفعل الأمراض لحبيوانية حمانة نطابة

حماية صحة الانسان وثقة المستهلك لأن تدابير الأمن الحيوي ضرورية لحماية المستهلك الذي يمكن أن يتعرض بمخاطر صحية حادة صماية صحة

وحسب (Austic et al.,1990) و) فإننا نستطيع القول إن الهدف الأساسي والبارز من تطبيق إجراءات الأمن الحيوي في مز ار عنا هو :

ـ منع العو امل المسببة للأمر اض بكافة أشكالها من الوصول إلى هذه المزرعة حيث يمكن لهذه العو امل الممرضة أن تكون:

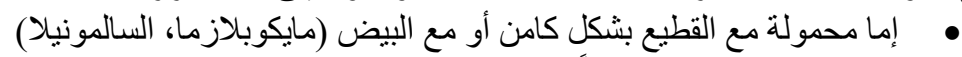

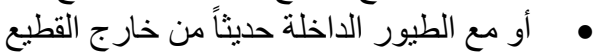

و إن القاعدة الأولى و الأساسية من الأمن الحيوي و هي دخول الكل معاً وخروج الكل معا ALL OUT/ALL IN حسب (Hofacre (and Rosales, 1995

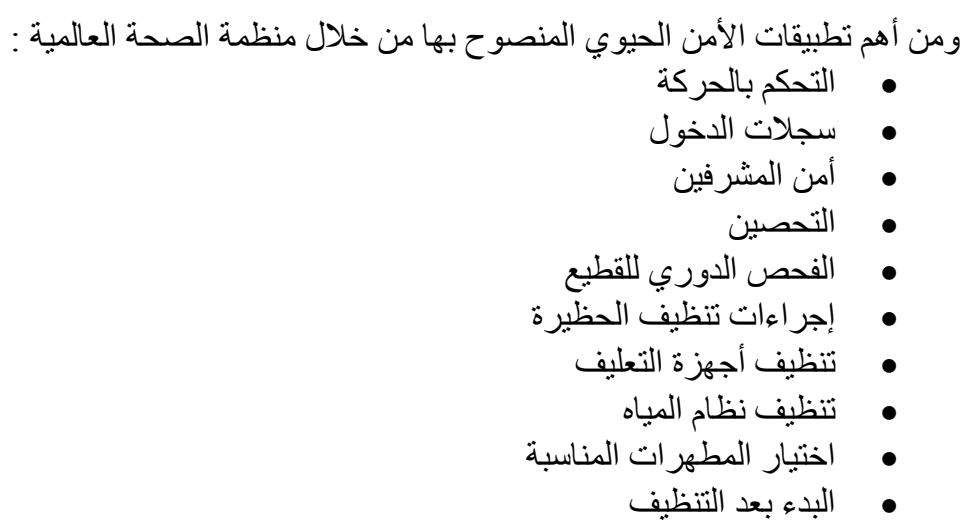

وقد أصبح مفهوم الأمن الحيوي هاماً جداً وضرورياً بشكل كبير (Mcllroy, 1998) حيث تكمن أهميته كونه يسـاعدنا على تحقيق الأهداف التالية:

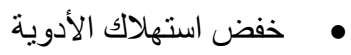
• • تحقيق إنتاج وأداء جيد للطبور الادور

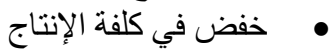
تحسين في نوعية المنتج في الأسواق المحلية والخارجية

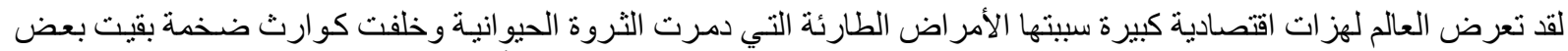

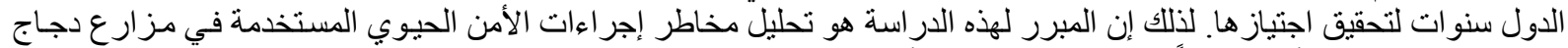

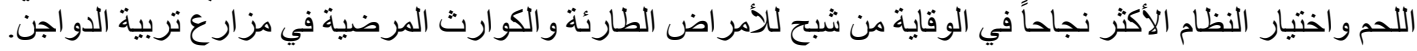

\section{MATERIALS AND METHODS \\ المواد والطرائق}

مواد العمل

ـ ـ مستلزمات أخذ العينة:

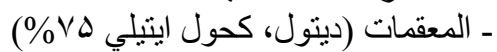
ـ كفوف بلاستيكية

ـ مسحات قطنية (Cotton Swabs) ـ - أطباق بيتري - و اقيات أرجل بلاستيكية

rـ المو اد المستعملة للفحص المخبري:

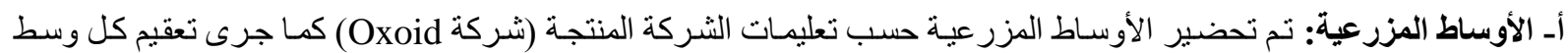

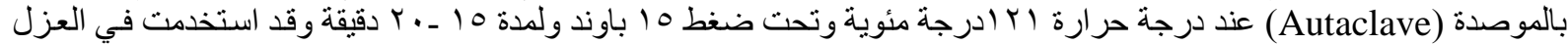

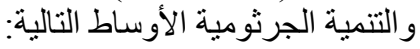


وسط الآغار المدمم Blood Agar استخدم وسط الآغار الصلب كأسـاس ثم أضيف إليهـ بعد التعقيم و التبريد دم الأغنام بنسبة ه\% ثم صب في أطباق بيتري معقة حيث استخدم للعزل الجرثومي الأولي بالإضافة إلى معرفة مقدرة الجر اثثيم على التى

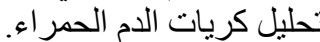

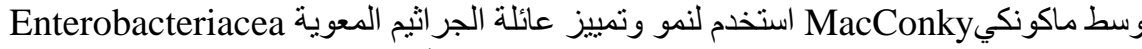
وسط المرق المغذي Nutrient Agarاستخدم هذا الوسط كأول خطوة للعزل البكتيري وذلك لتحفيز الجر اثثم على النمو بعد أخذ العينة مباشرة

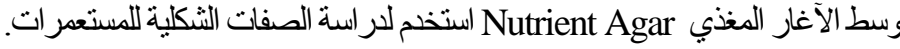

Staphylococcus وسط ملح المانيتول Manithol Salt Agar استخدم للكثف عن المكورات العنقودية الذهبية

Aureus

وسط إدوارد Streptococcus لتمييز جر اثيم العقديات Edward Medium

بـ المحاليل و الكواشف المستعملة في الفحوصات الكيموحيوية:

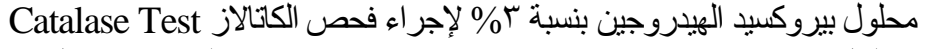

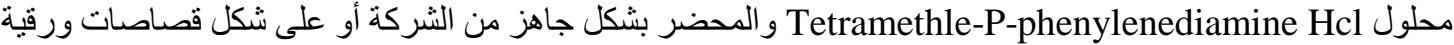
Oxidase Test جاهزة من الثركة أو أعمدة أو أنابيب زجاجية شعرية لغرض إجر اء فحص الأوكسيداز

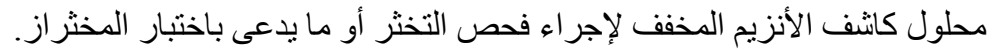

$$
\text { ج- الصبغات: صبغة غرام Gram's stain لمعرفة الجر اثثم الموجبة أو السالبة لصبغة غرام }
$$

دـ المطهرات المستخدمة في عملية تطهير الحظائر والمواد الثابتة والمتحركة في حظائر الدراسة:

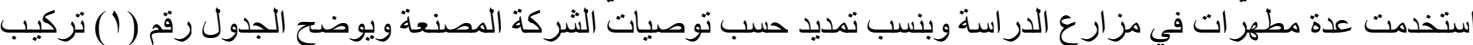

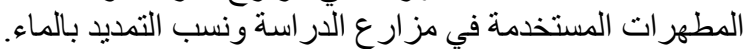

الجدول رقم ا : تركيب المطهر ات المستخدمة ونسب التمديد بالمياه حسب توصيات الثركة المصنعة.

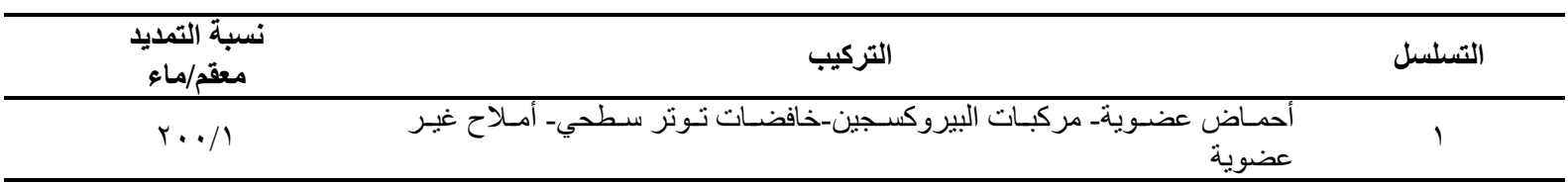

$\varepsilon \cdots / 1$

رباعيات كلور الأمونيوم بنو عين:ألكيل ديميثيل بنزيل أمونيوم كلور ايدــ داي ديسيل

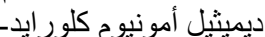
جلوتاريك ألاهيد ـ كحول إئرول إيزوبروبانول- زيت التربنتين

\begin{tabular}{|c|c|c|}
\hline $1 \cdots / 1$ & مشتقات رباعيات كلور الأمونيوم-غليوكسالـ غلوتر ألدهيد- فورم ألدهيد & r \\
\hline $10 . / 1$ & أحماض عضوية_ مضادات عضوية_ مو اد حالة & $\varepsilon$ \\
\hline$r 0 \cdot / 1$ & مشتقات رباعيات كلور الأمونيوم- خافضات التوتر السطحي & 0 \\
\hline$\varepsilon \cdots / 1$ & كحول إلديد-غليوكسال كلور الأمونيوم (ألكيل بنزيل أمونيوم كلور ايد)- جلوتاريك ألد & 7 \\
\hline $1 \cdots / 1$ & مشتقات الفينولـ مركبات الكريزولـ مو اد مزيلة & $\checkmark$ \\
\hline
\end{tabular}

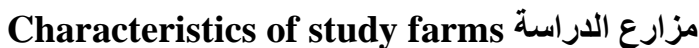

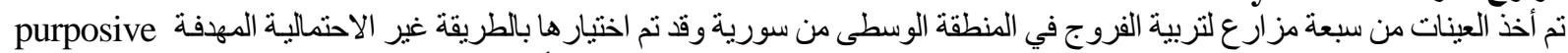

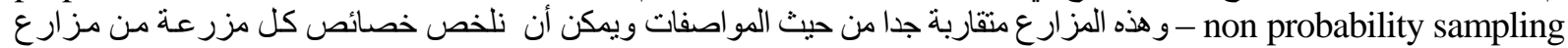
الدر اسة بما يلي:

نمط التربية: التربية شبه مغلقة

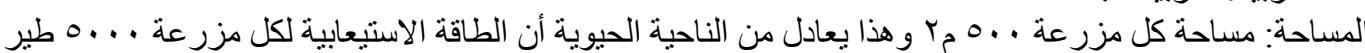

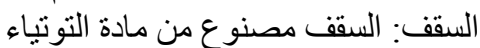
الجدران: الجدران إسمنتية ولوحظ وجود التوة التقوب و الثقوق فيها 


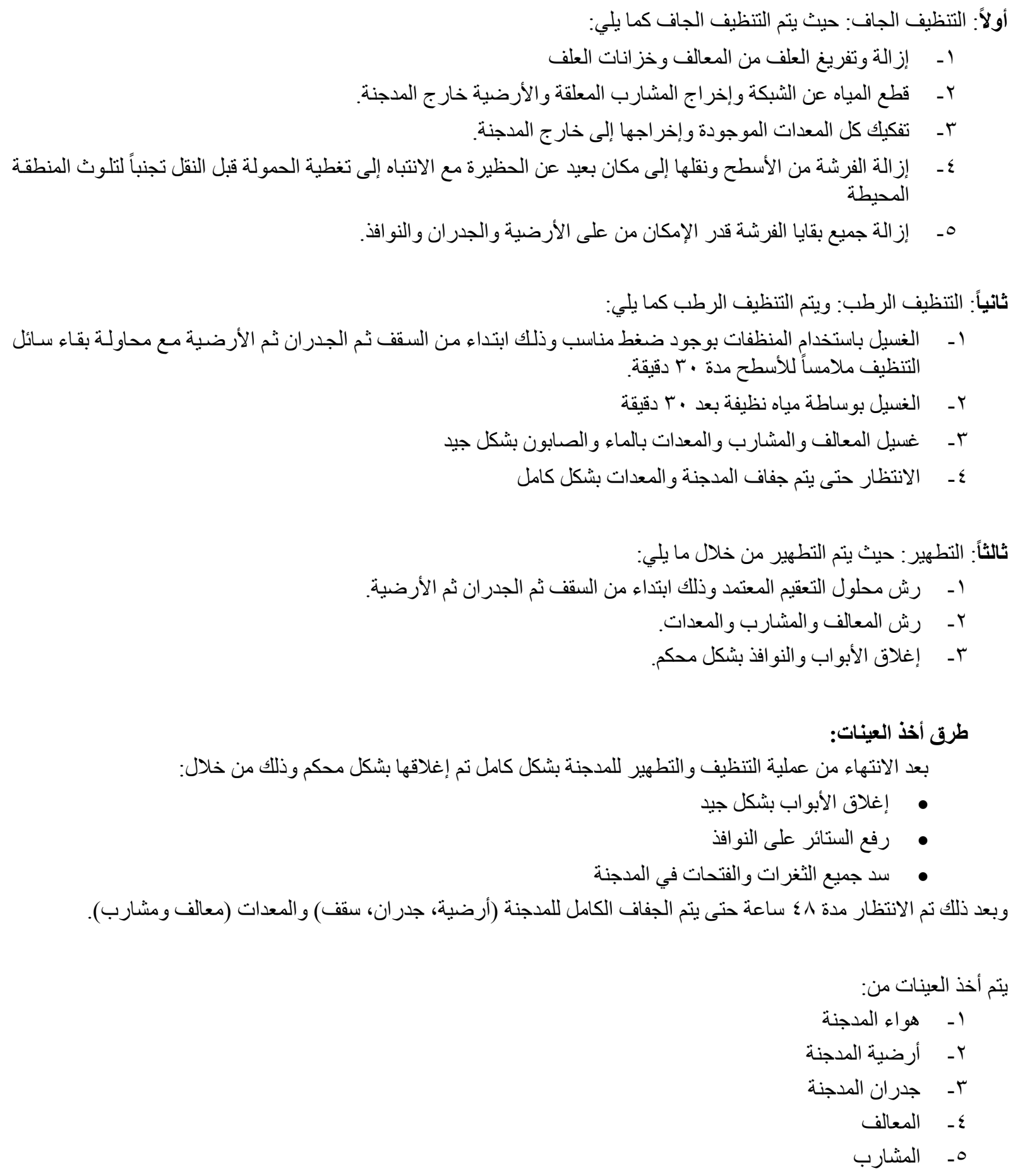

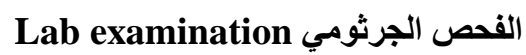

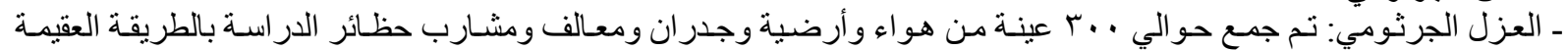

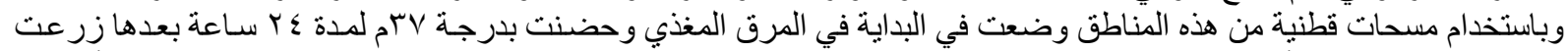

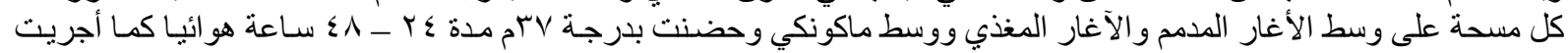

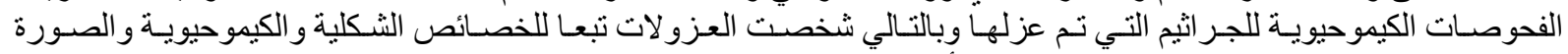

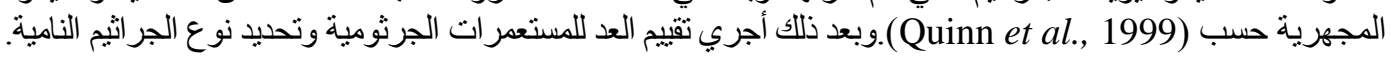

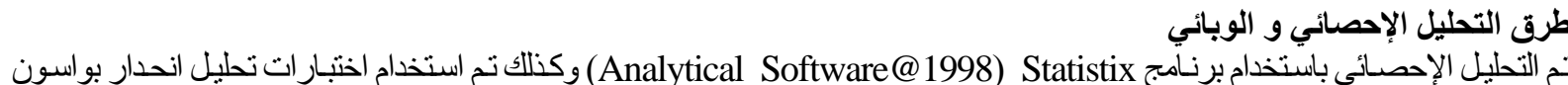
.Poission Regression Analysis 


\section{RESULTS \\ النتائسج}

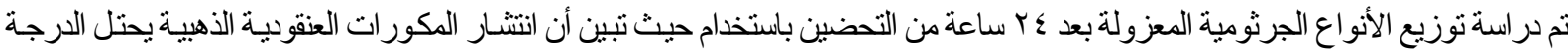

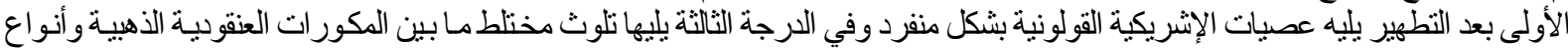

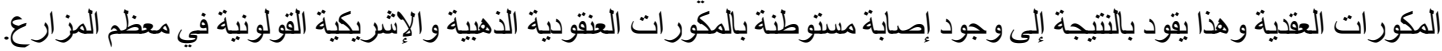
ويوضح الجدول رقم (Y) العزولات الجرثومية الموجودة بعد الستخدام المطهرات.

الجدول رقم Y : العزولات الجرثومية بعد استخدام المطهرات المختلفة في مزارع الدراسة.

\begin{tabular}{|c|c|}
\hline 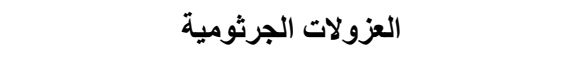 & 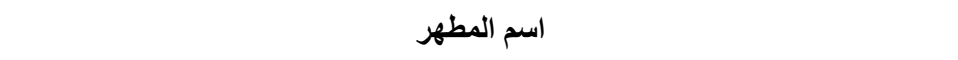 \\
\hline المكور ات العنقو ديةـ الإشريكية القولونية_ باستوريلا. & أحماض عضوية؛ مركبات البيروكسجين؛ خافضات توتر سطحي؛ أملاح غير عضوية \\
\hline المكور ات العنقودية & مشتقات الفينول-مركبات الكريزول-مو اد مزيلة \\
\hline المكور ات العنقوديةـ الإشريكية القولونية & غليوكسالـ كحول إيزو بروبات كلون (ألكيل بنزيل أمونيوم كلور ايد)- جلوتاريك ألدهيد- فورم ألدهيد- \\
\hline المكور ات العنقودية_ المكور ات العقديةــ باستوريلا & مشتقات رباعيات كلور الأمونيوم- خافضات التوتر السطحي \\
\hline المكور ات العنقودية_ المكور لقات العقدية_ الإشريكية & 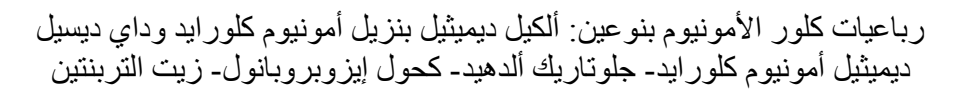 \\
\hline 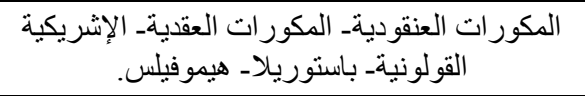 & مشتقات رباعيات كلور الأمونيوم- غليوكسال_غلوتر ألدهيد- فورم ألدهيد \\
\hline المكور ات العنقودية_ المكورات العقدية_ الإشريكية & أحماض عضوية_ـ مضـادات عضوية_ـ مو اد حالة \\
\hline
\end{tabular}

وباستخدام تحليل انحدار بو اسون لتقييم المطهر ات المستخدمة بعد عمليات أخذ العينات للفحص الجرثومي فقد تبين أن مركبات الفينول

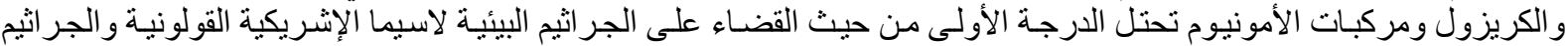

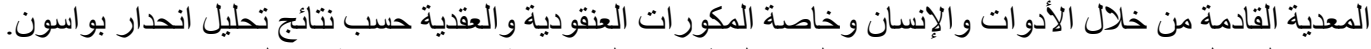

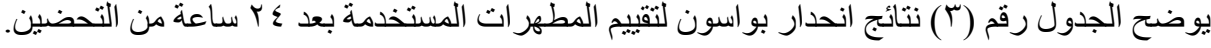

الجدول رقم ؟ّ: نتائج انحدار بو اسون لتقييم المطهر ات المستخدة بعد ؟r ساعة من التحضين.

\begin{tabular}{|c|c|c|c|c|}
\hline 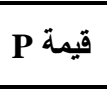 & المعامل/الخطأ & الخطأ المعياري & تفاعل بواسون & المتغيرات (المطهرات) \\
\hline$\because \cdots$ & $|r| . V \mid$ & $\because \cdot r \leq$ & $r . . .7$ & 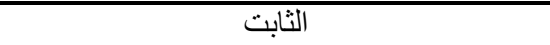 \\
\hline$\because \cdots$ & $-17.0 \mathrm{~V}$ & $\cdot 1 \cdot \varepsilon$ & $-1 . V \Gamma \wedge$ & خافضات توتر سطوية؛ مركبات أملاح غيروكسجين؛ عضوية \\
\hline$\because \cdots$ & $-10 . Y \varepsilon$ & $\because \wedge 7$ & $-1 . r 14$ & مشتقات الفينول- مركبات الكريزول- مو اد مزيلة \\
\hline$\because \cdots$ & $-\varepsilon .91$ & $\because .0 \leqslant$ & $-\cdot .479$ & 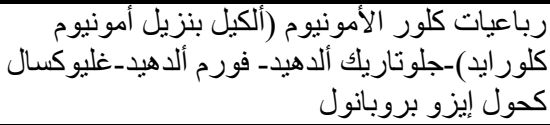 \\
\hline$\because \cdots \varepsilon$ & - r.or & $\because .04$ & $-\cdot .1 \wedge 7$ & خافضتقات رباعيات كلور الأمونيوم \\
\hline$\because \cdots r$ & מד. & $.0 \mathrm{Or}$ & $-\cdot .194$ & 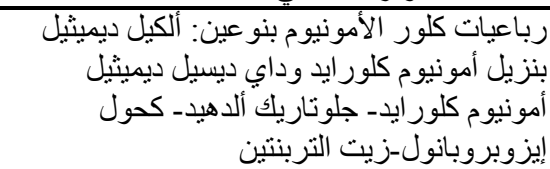 \\
\hline$\because \cdots$ & 0.91 & $\because \cdot \leq \leqslant$ & $\because$ YTA & 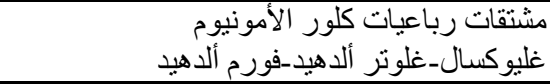 \\
\hline$\because \cdots$ & $1 \wedge . \cdot 1$ & $\because \cdot \mu$ & $\because V \cdot \varepsilon$ & أحماض عضو ية= مضادات عضوية_ مو اد حالة \\
\hline
\end{tabular}

ومن خلال الجدول السابق واستخدام القانون التالي يمكن حساب قيمة معدل حدوث الكثافة

In: IDR $=$ Antilog of coeffiecient

(IDR) Incidence Density Rate

95\% Ln: IDR $=$ Antilog of coeff \pm 1.96 STR 


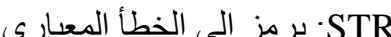

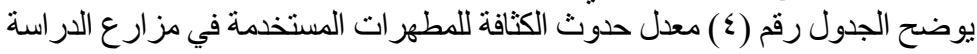
الجدول رقم ؛ : معدل حدوث الكثافة للمطهر ات المستخدمة في مزارع الدر اسة.

\begin{tabular}{|c|c|c|c|}
\hline $\begin{array}{c}95 \% \\
\text { IDR } \\
\text { Upper limit }\end{array}$ & $\begin{array}{c}95 \% \\
\text { IDR } \\
\text { Lower limit }\end{array}$ & IDR & اسم المطهز \\
\hline$\because r \cdot$ & .109 & $\because 11$ & أحماض عضوية_ مركبات البيروكسجين- خافضات توتر غير عضية \\
\hline 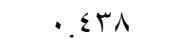 & $\cdot 1 \cdot 1$ & $\cdot T V$ & مشتقات الفينولـ مركبات الكريزولـ مو اد مزيلة \\
\hline$\cdot \wedge T V$ & $.70 \mathrm{r}$ & $\because V 7$ & 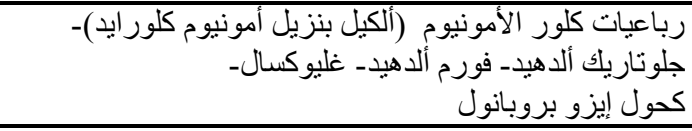 \\
\hline$\cdot 9 r \leq$ & $\because \vee Y_{O}$ & $\cdot \wedge r$ & مشتقات رباعبات كلور الأمونيوم-خافضات التوتر السطحي \\
\hline $.9 T \leq$ & $\because \vee 10$ & $\because \wedge r$ & 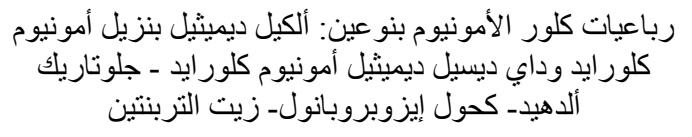 \\
\hline r.IVA & $\cdot(\{r)$ & $1 . r$ & فورم ألدهيد رباعيات كلور الأمونيوم- غليوكسال- غلوتر ألدهيد- \\
\hline$r . \wedge T$ & 1.9r & $r .1$ & أحماض عضوية_ـ مضادات عضويةــ مو اد حالة \\
\hline
\end{tabular}

\section{DISCUSSIONAND CONCLUSIONS المناقشة والاستنتاجات}

تعتبر إجر اءات الأمن الحيوي الوسبلة الوحيدة التي يمكن من خلالها الوقاية من المسبيات المرضية الجرثومية والفيروسية في أفواج التربية التالية كما يمكن من خلالها القضاء على العو ائل (الأثوياء) الناقلة لهذه المسبيات (Hanson, 2007).

وبالمفهوم العملي فإن الأمن الحيوي يتضمن الوقاية من كافة العوامل المرضية التي تتنقل إلى الطيور من خلال الأشخاص و الأدو ات ومخلفات الطيور و الحيو انات البرية و الحشرات و العلف و المياه و الحيو انات المنزلية ولية ووسائل النقل (Helm, 2005).

وباتباع إجر اءات الأمن الحيوي المنصوح بها من قبل العديد من المر اكز العلمية والمر اكز الإرشـادية في اسكوتلندا (Defra, 2005) وكذلك حسب الباحث (Marishita, 2007) نستطيع أن نقوم بالوقاية و التحكم بالأمر اض. الكر.

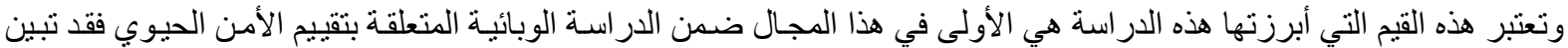

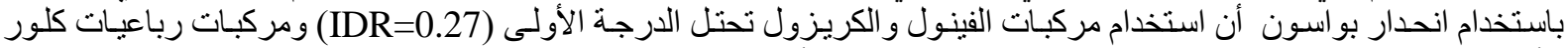

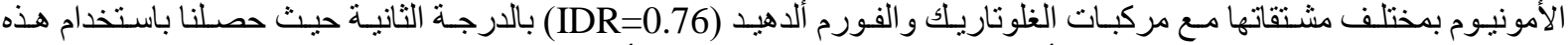

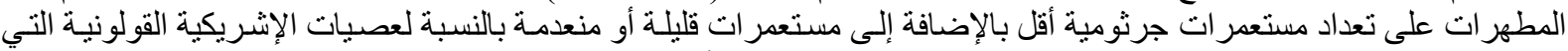

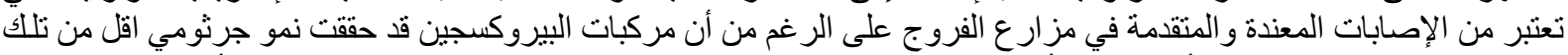

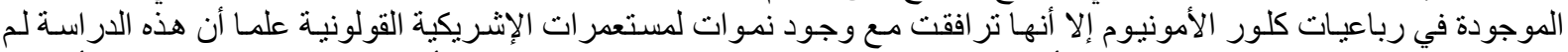

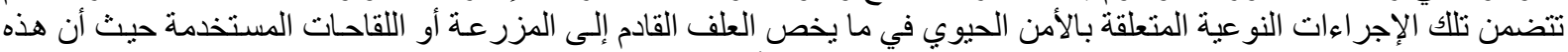

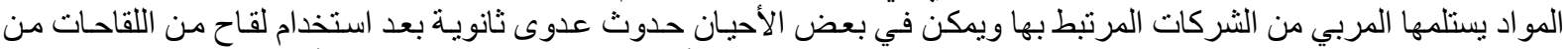

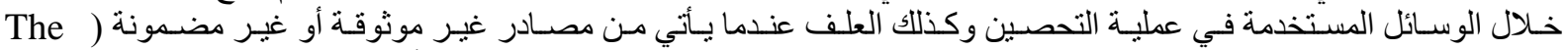

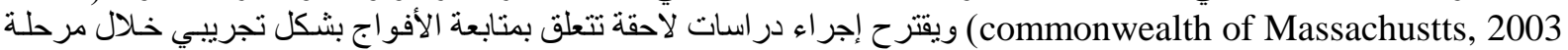
التعليف و التحصين لمختلف مر احل التربية ليكون تقييم إجراءات الأمن الحيوي بشكل متكامل.

\section{REFERENCES المراجـ}

Defra (2005): Biosecurity and Preventing disease. Scotlish Executive, Department for Environment food and Rural Affairs. University of Scotland, UK. 
Dekich, M. (1995): Principles of disease prevention in commercial integrated broiler operations, in: Biosecurity in the poultry industry. American Association of Avian Pathologists University of Pennsylvania, New Bolton Center, Kennett Square, PA, pp.85-94.

Hanson, G. (2007): Biosecurity for the Poultry Industry. Extension Poultry Department. West Virgina University, USA.

Helm, J. (2005): Biosecurity on Poultry Farms Clemson university, Livestock Poultry Health Programs.

Hofacre, CL. and Rosales, A.G. (1995): Prevention of disease in primary and multiplier broiler breeder operations, in: Biosecurity in the poultry industry. American Association of Avian Pathologists, University of Pennsylvania, New Bolton Center, Kennett Square, PA, pp. 79-84.

Marishita, T.Y. (2007): Biosecurity for Poultry. The OHIO state university, USA.

Mcllroy, S.G.(1998):Control of salmonella contamination of poultry feeds. Proceedings of the International Symposium on Food-Borne Salmonella in Poultry. American Association of Avian Pathologists, Baltimore, Maryland, pp. 83-87.

Natural Resource, Agriculture, and Engineering Service NRAES-132.

Poultry Waste Managemen Handbook (1999): (http://www.nraes.org/publications/nraes132.HTML).

Poultry Production (1990): R.E. Austic and M.C. Nesheim. Lea andFebiger, Philadelphia, PA.

Poultry Science and Production (1985): R.E. Moreng and J.S. Avens. Reston Pubi. Co., Inc., Reston, VA.

Quinn, P.J.; Carter, M.E.; Markey, B.K. and Carter, G.R. (1999): clinical veterinary microbiology. Mosby Har court publishers limit. USA.

The Commonwealth of Massachusetts (2003): Biosecurity for Poultry Facilities. Executive office of Environmental Affairs, Department of Food and Agriculture, Boston, USA. 